\title{
Peripheral T-cell lymphoma unspecified (PTCL-U): a new prognostic model from a retrospective multicentric clinical study
}

Andrea Gallamini, Caterina Stelitano, Roberta Calvi, Monica Bellei, Daniele Mattei, Umberto Vitolo, Fortunato Morabito, Maurizio Martelli, Ercole Brusamolino, Emilio lannitto, Francesco Zaja, Sergio Cortelazzo, Luigi Rigacci, Liliana Devizzi, Giuseppe Todeschini, Gino Santini, Maura Brugiatelli and Massimo Federico

Updated information and services can be found at:

http://bloodjournal.hematologylibrary.org/content/103/7/2474.full.html

Articles on similar topics can be found in the following Blood collections

Clinical Trials and Observations (3447 articles)

Neoplasia (4217 articles)

Information about reproducing this article in parts or in its entirety may be found online at:

http://bloodjournal.hematologylibrary.org/site/misc/rights.xhtml\#repub_requests

Information about ordering reprints may be found online at:

http://bloodjournal.hematologylibrary.org/site/misc/rights.xhtml\#reprints

Information about subscriptions and ASH membership may be found online at:

http://bloodjournal.hematologylibrary.org/site/subscriptions/index.xhtml

Blood (print ISSN 0006-4971, online ISSN 1528-0020), is published weekly

by the American Society of Hematology, 2021 L St, NW, Suite 900,

Washington DC 20036.

Copyright 2011 by The American Society of Hematology; all rights reserved.

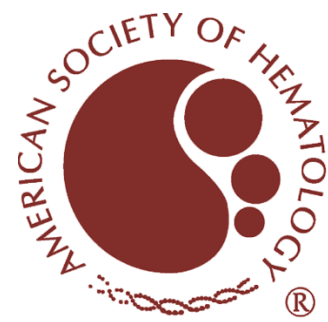




\section{Peripheral T-cell lymphoma unspecified (PTCL-U): a new prognostic model from a retrospective multicentric clinical study}

Andrea Gallamini, Caterina Stelitano, Roberta Calvi, Monica Bellei, Daniele Mattei, Umberto Vitolo, Fortunato Morabito, Maurizio Martelli, Ercole Brusamolino, Emilio lannitto, Francesco Zaja, Sergio Cortelazzo, Luigi Rigacci, Liliana Devizzi, Giuseppe Todeschini,

Gino Santini, Maura Brugiatelli, and Massimo Federico, for the Intergruppo Italiano Linfomi

To assess the prognosis of peripheral T-cell lymphoma unspecified, we retrospectively analyzed 385 cases fulfilling the criteria defined by the World Health Organization classification. Factors associated with a worse overall survival (OS) in a univariate analysis were age older than 60 years $(P=.0002)$, equal to or more than 2 extranodal sites $(P=.0002)$, lactic dehydrogenase (LDH) value at normal levels or above $(P<.0001)$, performance status (PS) equal to or more than 2 $(P \leq .0001)$, stage III or higher $(P=.0001)$, and bone marrow involvement $(P=.0001)$. Multivariate analysis showed that age (relative risk, 1.732; 95\% Cl, 1.300-2.309; $P<.0001$ ), PS (relative risk, 1.719; 95\% Cl, 1.269-2.327, $P<.0001$ ), LDH level (relative risk, 1.905; 95\% Cl, 1.415-2.564; $P<.0001$ ), and bone marrow involvement (relative risk, 1.454; $95 \% \mathrm{Cl}, 1.045-$ 2.023; $P=.026$ ) were factors independently predictive for survival. Using these 4 variables we constructed a new prognostic model that singled out 4 groups at different risk: group 1, no adverse fac- tors, with 5-year and 10 -year OS of $62.3 \%$ and $54.9 \%$, respectively; group 2 , one factor, with a 5-year and 10-year OS of $52.9 \%$ and $38.8 \%$, respectively; group 3, 2 factors, with 5 -year and 10-year OS of $32.9 \%$ and $18.0 \%$, respectively; group 4,3 or 4 factors, with a 5-year and 10-year OS of 18.3 and $12.6 \%$, respectively $(P \leq .0001$; log-rank, 66.79). (Blood. 2004;103: 2474-2479)

(c) 2004 by The American Society of Hematology

\section{Introduction}

In Western countries peripheral T-cell non-Hodgkin lymphomas (PTCLs) account for $15 \%$ to $20 \%$ of aggressive lymphomas ${ }^{1}$ and for $7 \%$ to $10 \%$ of all the non-Hodgkin lymphomas (NHLs). ${ }^{2,3}$ They usually occur in middle-aged to elderly patients, and presenting features are characterized by a disseminated disease in $68 \%$ of the patients, with systemic symptoms in nearly half of them (45\%), bone marrow (BM) involvement in a quarter $(25.8 \%)$, and extranodal disease in a third (37\%). Despite aggressive therapy, the prognosis is dismal, with more than half the patients dying of their disease. ${ }^{2}$

The influence of the immunophenotype on the outcome of aggressive NHL has long been questioned ${ }^{4,5}$; in the more recent literature, however, most authors agree on the adverse prognostic meaning of the T-cell phenotype per se, ${ }^{3,6-9}$ regardless of other well-defined clinical prognostic indexes such as the International Prognostic Index (IPI). ${ }^{10}$

In the past, a number of definite entities corresponding to recognizable subtypes of T-cell neoplasm, such as Lennert lymphoma, T-zone lymphoma, pleomorphic T-cell lymphoma, small and medium-sized, and large-cell T-cell lymphoma, and Timmunoblastic lymphoma have been described, ${ }^{11}$ but evidence that these correspond to distinctive clinicopathologic entities is still lacking. ${ }^{2,8,9,12}$ For this reason the recent World Health Organization (WHO) classification of the hematopoietic and lymphoid neoplasms has collected these under the single broad category of "peripheral T-cell lymphoma, unspecified (PTCL-U). ${ }^{13}$ The natural history of PTCL seems to be unchanged by the use of second- and third-generation chemotherapy regimens ${ }^{8}$ and 5-year overall survival (OS) still remains between $25 \%$ and $47 \%$. $^{2-3,6-11}$ Although high-dose sequential (HDS) chemotherapy followed by autologous hematopoietic stem cell transplantation (ASCT) has been successfully performed in 2 small series of patients, ${ }^{14,15}$ others ${ }^{16,17}$ in a large cohort of high-risk NHL treated with HDS chemotherapy followed by ASCT have definitely demonstrated no benefit of autologous bone marrow transplantation in the subset of T-cell lymphomas. ${ }^{14}$

To better define the clinical outcome of T-cell lymphomas grouped within the broad category of PTCL-U as a single entity,
From the Struttura Complessa (S.C.) Ematologia, Azienda Ospedaliera S. Croce e Carle, Cuneo, Italy; Divisione di Ematologia, Azienda Ospedaliera Bianchi-Melacrino-Morelli, Reggio Calabria, Italy; Cattedra di Oncologia Medica, Università di Modena e Reggio Emilia, Modena, Italy; S.C. Ematologia, Azienda Ospedaliera S. Giovanni Battista, Torino, Italy; Centro Trapiant Midollo Osseo, Azienda Osp. Bianchi-Melacrino-Morelli, Reggio Calabria, Italy; Divisione di Ematologia, IRCCS Policlinico S. Matteo-Pavia, Italy; Dipartimento di Oncologia, Unità di Ematologia e TMO, Università di Palermo, Palermo, Italy; Dipartimento di Biotecnologie Cellulari ed Ematologia, Università La Sapienza Roma, Italy; Clinica Ematologica, Dip. to Ricerche Mediche e Morfologiche, Policlinico Università, Udine, Italy; Divisione di Ematologia, Azienda Ospedaliera Ospedali Riuniti di Bergamo, Bergamo, Italy; Cattedra e Divisione di Ematologia, Padiglione S. Luca, Policlinico Careggi, Firenze, Italy; Divisione di Oncologia Medica C, Istituto Nazionale Tumori, Milano, Italy; Cattedra di Ematologia, Università di Verona, Verona, Italy; Divisione di Ematologia,
Azienda Ospedaliera Ospedale S. Martino, Genova, Italy; and Divisione di Ematologia, Azienda Ospedaliera Papardo, Messina, Italy.

Submitted September 8, 2003; accepted November 13, 2003. Prepublished online as Blood First Edition Paper, November 26, 2003; DOI 10.1182/blood2003-09-3080

A list of participating institutions and principal investigators of the Intergruppo Italiano Linfomi appears in the "Appendix."

Reprints: Andrea Gallamini, S.C. Ematologia Az. Ospedaliera S. Croce e Carle Via M. Coppino, 26-12100 Cuneo, Italy; e-mail: gallamini.a@ospedale.cuneo.it.

The publication costs of this article were defrayed in part by page charge payment. Therefore, and solely to indicate this fact, this article is hereby marked "advertisement" in accordance with 18 U.S.C. section 1734.

(C) 2004 by The American Society of Hematology 
Table 1. Histologic PTCL-U subtypes

\begin{tabular}{lcc}
\hline \multicolumn{1}{c}{ Description } & No. of cases & \% of cases \\
\hline PTCL-U NOS & 162 & 42.0 \\
Large cell & 71 & 18.4 \\
Large + medium-sized cell & 64 & 16.6 \\
Pleomorphic cell & 31 & 8.0 \\
Small cell & 23 & 5.9 \\
Lymphoepithelioid & 19 & 4.9 \\
T-zone & 15 & 3.8 \\
\hline
\end{tabular}

and to assess a prognostic model specifically devised for patients with this uncommon disease, the Intergruppo Italiano Linfomi (IIL) promoted a large, retrospective, collaborative study. Here we report the results of this study, performed on 385 newly diagnosed patients followed at participating institutions between January 1989 and December 2001.

\section{Patients and methods}

Among 10315 cases of lymphoma recorded through June 2002 at the IIL Lymphoma Registry, we selected all cases of PTCL diagnosed between January 1989 and December 2001. A preliminary working file containing information on 512 cases, fulfilling all the characteristics of "Peripheral TCell Lymphoma, Unspecified," was created.

Thereafter we considered eligible for the study all patients with: (1) histologically confirmed diagnosis of PTCL-U, according to the WHO classification. ${ }^{13}$ Distinctive entities, formerly classified as PTCL and characterized by a definite clinical picture (such as angioimmunoblastic T-cell lymphoma, anaplastic large-cell lymphoma [ALCL], entheropathyassociated T-cell lymphoma, nasal-type T-cell lymphoma, or primary cutaneous T-cell lymphoma), were excluded from the analysis. No cases of T-prolymphocytic leukemia, adult T-cell leukemia/lymphoma, or primary hepatosplenic T-cell lymphoma were recorded. (2) Proven T-cell phenotype either by immunohistochemistry, flow cytometry, or rearrangement of T-cell receptor. Additional criteria for inclusion were (3) availability of a complete set of clinical data for an accurate clinical staging, including diagnostic biopsy with immunohistochemistry or flow cytometry (or both), complete blood count, biochemistry, whole body computed tomography (TC) scan, or ${ }^{67} \mathrm{Ga}$ scintigraphy, and $\mathrm{BM}$ trephine biopsy and (4) a minimum follow-up of 1 year, with the last observation recorded no more than 6 months before data collection.

Of 512 cases retrieved from the Registry for the primary working file we excluded 127 patients for the following reasons: 23 exhibited clinical characteristics and a histologic description of "nasal-type" T-cell lymphoma, 47 for incomplete clinical data, 21 for unproven T-cell phenotype, and 36 for inadequate follow-up. The participating centers were asked for a simple set of clinical data including age, sex, complete blood count, erythrocyte sedimentation rate (ESR), lactic dehydrogenase (LDH) level, and serum $\beta_{2}$-microglobulin level. Ann Arbor stage, IPI, number and sites of extranodal disease, BM involvement, systemic symptoms, bulky disease, PS, date of diagnosis, type of treatment, response to therapy, date of assessment of response, date of relapse, date of last follow-up, status (alive or deceased), and, if deceased, date and cause of death. Bulky disease was defined as a mass with the largest diameter greater or equal to $10 \mathrm{~cm}$ or, for the mediastinum only, a mass lager than one third of the chest diameter. Systemic symptoms were defined, according to Ann Arbor criteria, as recurrent fever $\left(>38^{\circ} \mathrm{C}\right)$, night sweats, or loss of a more than $10 \%$ of body weight.

Response to treatment was assessed 1 month after the end of induction therapy by performing all the examinations with pathologic values at baseline, which concurred to define the stage. Complete remission (CR) was defined as the disappearance of all clinical evidence of the disease and the normalization of all laboratory values and radiologic findings that had been considered abnormal before starting therapy. Partial remission (PR) was defined as a more than $50 \%$ reduction, for at least 1 month, of the largest dimension of each measurable anatomic site of disease localization. Nonresponse (NR) was defined as a less than 50\% regression of tumor size, or stable/progressive disease. All the deaths occurring because of disease progression or related to treatment toxicity were considered as treatment failures, and the patients were included in the NR group.

\section{Histologic findings}

Table 1 lists the different histologic subtypes conforming to the PTCL-U diagnosis. The most frequent subtype (189 of $385,49.1 \%$ ) was characterized by a simple cytologic description of the tumor and included a number of subentities (large cell, large and medium-sized cell, pleomorphic cell, small cell) differing in cell size and the relative proportion of large or small cells. Other categories were PTCL-U not otherwise specified (PTCL-U NOS), T-zone lymphoma, lymphoepithelioid lymphoma (or Lennert lymphoma). In 290 cases the T phenotype was proven on immunohistochemical grounds, in 73 cases by cytofluorimetric assay of a fresh cellular suspension, and in 22 cases by rearrangement of T-cell receptor.

\section{Treatment strategies}

Patients were grouped in 4 main categories (Table 2), according to the treatment strategy adopted: (1) only supportive care, 7 (2\%) of 385; (2) nonanthracyclin chemotherapy, $32(8 \%)$ of 385 ; (3) anthracyclin-based chemotherapy, $302(78 \%)$ of 378 ; and (4) autologous or allogeneic BM transplantation as part of a primary treatment, $44(12 \%)$ of 385 .

\section{Statistical analysis}

All data were analyzed with the Statistical Package for the Social Sciences (SPSS). ${ }^{18}$ OS and relapse-free survival (RFS) curves were calculated according to the Kaplan and Meier method. ${ }^{19}$ OS was calculated from the date of diagnosis until death from any cause or date of last contact for living patients. For patients in CR, RFS was calculated from the date of diagnosis to the first evidence of relapsing disease. The association between clinical factors and the probability of attaining CR was evaluated by likelihood ratio $\chi^{2}$ test. In cases where the date of the therapy onset was not available, the survival was calculated from the date of the diagnosis until the date of the last follow-up or death. RFS was applied only in patients attaining CR and was calculated from the end of first-line therapy to relapse. The univariate association between individual clinical features and OS were determined with the log-rank test. ${ }^{20}$ Factors independently associated with OS were identified in multivariate analysis by the Cox proportional hazards regression model. ${ }^{21}$ The limit of significance for all analyses was defined as a $P$ value of .05; 2-sided tests were used in all calculations.

\section{Results}

The characteristics of the 385 patients fulfilling the inclusion criteria and entered into the study are summarized in Table 3.

The median age was 54 years (range, 15-96 years), and there was a male preponderance, with a male- to-female ratio of 1.83 . Disease extension and frequency of extranodal sites (ENSs) were suggestive of an aggressive onset: $291(76.1 \%)$ of 385 were in stage III or IV, and 192 (49.9\%) of 385 in stage IV; more than two thirds ( 281 of $385,73 \%$ ) presented organ involvement. Table 4 shows the extranodal spread of the disease, with BM being the most frequent

\section{Table 2. Treatment strategies}

\begin{tabular}{lcc}
\hline \multicolumn{1}{c}{ Treatment } & No. of cases & \% of cases \\
\hline No therapy & 7 & 2 \\
Nonanthracyclin CT & 32 & 8 \\
CT with anthracyclin & 302 & 78 \\
HDS plus ASCT & 44 & 12 \\
\hline
\end{tabular}

CT indicates chemotherapy. 
Table 3. Clinical and biologic characteristics of the patients

\begin{tabular}{|c|c|c|c|}
\hline Characteristics & $\begin{array}{c}\text { No. of } \\
\text { patients }\end{array}$ & $\begin{array}{c}\text { No. of } \\
\text { patients available }\end{array}$ & $\%$ \\
\hline Age, $y$ & & 385 & \\
\hline 60 or younger & 234 & & 60.8 \\
\hline Older than 60 & 151 & & 39.2 \\
\hline \multicolumn{4}{|l|}{ Sex } \\
\hline Men & 249 & 385 & 64.7 \\
\hline Women & 136 & & 35.3 \\
\hline ECOG PS & & 383 & \\
\hline $0-1$ & 274 & & 71.2 \\
\hline $2-4$ & 109 & & 28.3 \\
\hline Ann Arbor stage & & 385 & \\
\hline I-II & 92 & & 23.9 \\
\hline IIII-IV & 293 & & 76.1 \\
\hline Systemic symptoms & & 385 & \\
\hline Yes & 175 & & 45.4 \\
\hline No & 210 & & 54.6 \\
\hline Bulky disease greater than $10 \mathrm{~cm}$ & & 385 & \\
\hline Yes & 58 & & 15.0 \\
\hline No & 327 & & 85.0 \\
\hline No. of ENSs & & 385 & \\
\hline $0-1$ & 224 & & 58.2 \\
\hline More than 2 & 161 & & 41.8 \\
\hline BM involvement & & 368 & \\
\hline Involved & 118 & & 32.1 \\
\hline Not involved & 250 & & 67.9 \\
\hline LDH level & & 350 & \\
\hline Normal & 191 & & 54.6 \\
\hline Higher than normal & 159 & & 45.4 \\
\hline IPI & & 346 & \\
\hline $1-2$ & 189 & & 54.6 \\
\hline $3-4$ & 157 & & 45.4 \\
\hline Hemoglobin level & & 352 & \\
\hline $\begin{array}{l}\text { Less than } 12 \mathrm{~g} / \mathrm{dL} \text { (men) or } \\
\text { less than } 10 \mathrm{~g} / \mathrm{dL} \text { (women) }\end{array}$ & 78 & & 22.1 \\
\hline $\begin{array}{l}\text { More than } 12 \mathrm{~g} / \mathrm{dL} \text { (men) or } \\
\text { more than } 10 \mathrm{~g} / \mathrm{dL} \text { (women) }\end{array}$ & 278 & & 78.9 \\
\hline
\end{tabular}

site $(118$ of $385,32.2 \%)$, followed by spleen (95 of $385,24.6 \%)$, liver (50 of $385,12.9 \%)$, Waldeyer ring (42 of $385,10.9 \%$ ), and skin $(39$ of $385,10.1 \%)$

Bulky disease was present in $58(15.1 \%)$ of 385 patients; mean hemoglobin value was $12.35 \mathrm{~g} / \mathrm{dL}$; (range, 6-17 g/dL); mean

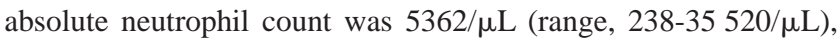
mean lymphocyte count $2323 / \mu \mathrm{L}$ (range, 165-75 072/ $\mu \mathrm{L}$ ); and mean platelet count $235345 / \mu \mathrm{L}$ (range, 3000-613 000/ $\mu \mathrm{L}$ ). Nearly half the patients presented with systemic symptoms (175 of 385, $45.5 \%$ ), and two thirds showed an ambulatory PS (Eastern Cooperative Oncology Group [ECOG] PS 0-1, 274 of 385, 71.2\%);

Table 4. Sites involved in 281 patients with extranodal involvement

\begin{tabular}{lrcr}
\hline \multicolumn{1}{c}{ Site } & $\begin{array}{r}\text { No. of } \\
\text { cases }\end{array}$ & $\begin{array}{c}\% \text { of } \\
\text { cases }\end{array}$ & $\begin{array}{r}\% \text { of all } \\
\text { ENSs }\end{array}$ \\
\hline BM & 118 & 30.6 & 41.9 \\
Spleen & 95 & 24.6 & 33.8 \\
Liver & 50 & 12.9 & 17.7 \\
Waldeyer ring & 42 & 10.9 & 14.9 \\
Skin & 39 & 10.1 & 13.8 \\
Lung + pleura & 38 & 9.8 & 13.5 \\
Gut & 35 & 9.0 & 12.4 \\
Bone & 18 & 4.6 & 6.4 \\
Soft tissues & 5 & 1.2 & 1.7 \\
Others & 54 & 14.02 & 19.2 \\
\hline
\end{tabular}

lactate dehydrogenase (LDH) levels were elevated in one third of the cases $(>1 \times$ normal value, 159 of $350,45.4 \%)$.

IPI scoring was available in $346(89.9 \%)$ of 385 of the patients; accordingly $98(28.3 \%)$ patients were classified as low risk (0-1), $91(26.3 \%)$ as intermediate-low ${ }^{2} ; 93(26.9 \%)$ as intermediatehigh, ${ }^{3}$ and $64(18.5 \%)$ as high risk.., 5

\section{Analysis of response}

In 6 of 385 patients the response to therapy was not recorded and in 7 patients no therapy was given; therefore information on 372 patients was available for treatment response. Overall, the CR rate was $53.2 \%$ (198 of 372); PRs were observed in $20.7 \%$ (77 of 372) and failures in $26.1 \%$ (97 of 372). In univariate analysis the factors associated with a lower probability of achieving CR were advanced stage (III-IV) (odds ratio $[\mathrm{OR}]=2.781 ; 95 \% \mathrm{CI}, 1.656-4.671$; $P<.0001)$, the presence of ENSs (OR $=2.577$; 95\% CI, 1.688 $3.935 ; P<.0001)$, BM involvement $(\mathrm{OR}=2.501$; $95 \% \mathrm{CI}, 1.580$ 3.959; $P<.0001)$, poor PS $(\mathrm{OR}=2.213$; $95 \%$ CI, $1.393-3.517$; $P=.001)$, high LDH levels $(\mathrm{OR}=2.158 ; 95 \% \mathrm{CI}, 1.397-3.334$; $P=.001)$, age older than 60 years (OR $=1.719 ; 95 \%$ CI, 1.129 $2.618 ; P=.012)$, and low hemoglobin level $(\mathrm{OR}=1.708 ; 95 \%$ CI, $1.018-2.865 ; P=.042)$. IPI proved to be of highly significant prognostic value $(P<.0001)$.

The 5 characteristics that remained independently significant in multivariate analysis were: poor PS (OR $=2.381 ; 95 \%$ CI, 1.141 4.968; $P=.021)$, the presence of ENSs $(\mathrm{OR}=2.112 ; 95 \% \mathrm{CI}$, $1.106-4.032 ; P=.023)$, age older than 60 years $(\mathrm{OR}=2.144$; $95 \% \mathrm{CI}, 1.101-4.176 ; P=.025), \mathrm{BM}$ involvement $(\mathrm{OR}=2.169$; 95\% CI, 1.038-4.532; $P=.039$ ), and high LDH levels (OR $=2.127$; $95 \%$ CI, $1.018-4.441 ; P=.045)$.

\section{Analysis of survival}

After a mean follow up of 43.2 months, 229 (59.4\%) of 385patients had died, and the cumulative probability of survival at 5 years (Figure 1) was $43.0 \%$.

Forty-four percent of the deaths occurred in the first 12 months and an additional 23\% occurred in the following year. The 5-year and 10-year RFS among patients who achieved CR were $49.5 \%$ and $42.9 \%$, respectively. Factors significantly associated with prolonged response duration were early stage $(P=.00004)$, absence of BM involvement $(P=.0011)$, normal serum LDH levels $(P=.0150), \operatorname{good} P S(P=.0232)$, and female sex $(P=.0215)$.

The clinical parameters associated with reduced survival in univariate analysis are listed in Table 5: age older than 60 years $(P=.0002), 2$ or more ENSs $(P=.0002), \mathrm{LDH}$ level equal to or more than normal value $(P<.0001)$, PS equal to or more than 2

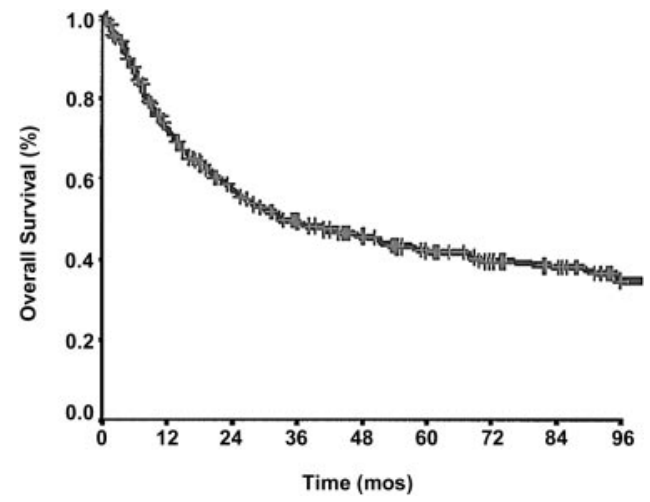

Figure 1. OS of 385 PTCL-U patients. Crosses mark censored cases. 
Table 5. Clinical parameters influencing survival in univariate analysis

\begin{tabular}{llr}
\hline \multicolumn{1}{c}{ Parameter } & \multicolumn{1}{c}{ Cut-off value } & \multicolumn{1}{c}{$\boldsymbol{P}$} \\
\hline Age, y & Older than 60 & .0002 \\
ECOG PS & 2 or higher & $<.0001$ \\
Stage & III or higher & .0001 \\
LDH level & More than 1 $\times$ normal value & $<.0001$ \\
ENSs & 2 or more & .0002 \\
IPI & L, I-L, I-H, H & $<.0001$ \\
BM & Infiltrated & .0001 \\
Response to CT & CR vs PR vs NR & $<.0001$ \\
\hline
\end{tabular}

L indicates low; I-L, intermediate-low; I-H, intermediate-high; $\mathrm{H}$, high.

$(P<.0001)$, advanced disease (stage $\geq \mathrm{III} ; P=.0001)$, BM involvement $(P=.0001), \beta_{2}$-microglobulin level (available in 109 of 385 patients) more than $2.7 \mathrm{ng} / \mathrm{mL}(P=.0231)$, less than complete response to the therapy $(P<.0001)$, and IPI $(P<.0001)$. Systemic symptoms and bulky disease were nonsignificant factors.

Excluding $\beta_{2}$-microglobulin, the 8 prognostic factors available in most patients (324 of 385) were significantly associated with prognosis in univariate analysis. All these cases were selected for developing a prognostic model.

\section{Prognostic model}

In multivariate analysis the factors that turned out to correlate significantly with survival were age $(P<.0001$; relative risk, 1.732 ; $95 \% \mathrm{CI}=1.300-2.309)$, PS $(P<.0001$; relative risk, $1.719 ; 95 \% \mathrm{CI}=1.269-2.327)$, LDH level $(P<.0001$; relative risk, $1.905 ; 95 \% \mathrm{CI}=1.415-2.564)$, and $\mathrm{BM}$ involvement $(P=.026$; relative risk, $1.454 ; 95 \% \mathrm{CI}=1.045-2.023$; Table 6$)$.

Because the relative risk associated with each of the 4 factors was comparable, we constructed a new prognostic model by combining these prognostic variables in the following way: group 1, no adverse factors; group 2, 1 factor; group 3, 2 factors; and group 4, 3 or 4 factors. This novel Prognostic Index for PTCL-U (PIT) model was able to efficiently identify 4 groups of patients with different outcomes (Figure 2; $P<.0001 ; \log$-rank, 66.79).

For the 64 patients in group 1 the 5-year and 10-year survival rates were $62.3 \%$ and $54.9 \%$, respectively; for the 108 patients in group $2,52.9 \%$ and $38.8 \%$; for the 83 patients in group 3, 32.9\% and $18.0 \%$; and for the 67 patients in group $4,18.3 \%$ and $12.6 \%$.

In the same cohort of 324 patients, the IPI predictive model, developed for aggressive B-cell NHL, was able to identify 4 categories of patients with different prognoses: low in 91 patients, intermediate-low in 86 patients, intermediate-high in 85 patients, and high in 62 patients. The 5-year and 10-year survival rates were $58.94 \%$ and $50.0 \%$, respectively, in the low-risk group; $45.6 \%$ and $32.3 \%$ in the intermediate-low risk group; $39.7 \%$ and $29.8 \%$ in the intermediate-high risk group; $18.3 \%$ and $9.15 \%$ in the high risk group $(P<.0001, \log$-rank 53.80; Figure 3$)$.

Table 6. Clinical parameters influencing survival in multivariate analysis

\begin{tabular}{lcccc}
\hline Parameter & $\begin{array}{c}\text { Significance, } \\
\boldsymbol{P}\end{array}$ & $\begin{array}{c}\text { Relative risk } \\
\text { (exp. B) }\end{array}$ & $\begin{array}{c}95 \% \mathrm{Cl}, \\
\text { low }\end{array}$ & $\begin{array}{c}95 \% \mathrm{Cl} \text {, } \\
\text { high }\end{array}$ \\
\hline Age & $<.0001$ & 1.732 & 1.300 & 2.309 \\
PS & $<.0001$ & 1.719 & 1.269 & 2.327 \\
LDH level & $<.0001$ & 1.905 & 1.415 & 2.564 \\
BM attainment & .026 & 1.454 & 1.405 & 2.023 \\
\hline
\end{tabular}

exp. B indicates survival probability A vs B.

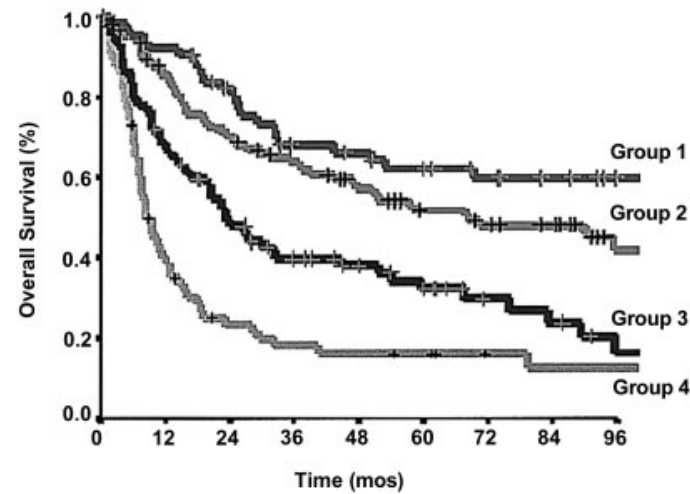

Figure 2. OS according to the proposed Prognostic Index for PTCL-U patients (PIT). Crosses mark censored cases.

Considering a simplified 2-class model both for IPI and PIT we found that $278(86.3 \%)$ of 322 patients were allocated in the same risk group using both indexes; the latter, however, showed a superior predictive power (log-rank 47.48 versus 28.91; Figure 4).

\section{Discussion}

Peripheral T-cell lymphomas are a heterogeneous group of neoplasms presenting as advanced disease and are characterized by widespread dissemination, aggressive behavior, and a very poor outcome. In the literature so far published the 5-year OS ranges between $25 \%$ and $45 \%$.,2,7-10,14,22 However, the meta-analysis of the prognosis of these neoplasms from the retrospective clinical reviews is somewhat cumbersome, due to the differences of the histologic subtypes accrued and of different follow-up times. Moreover, in 1994 the Revised European-American Lymphoma (REAL) classification and in 1997 the WHO classification introduced a substantial modification in the classification of these disorders. A number of different T-cell peripheral lymphomas, once considered as distinctive entities, are now collectively referred to as PTCL-U. Conversely, other lymphoma subtypes such as ALCL, formerly classified as peripheral T-cell lymphoma and characterized by a relatively good prognosis, were singled out, and considered separately. For example, in the largest series published so far on the prognosis of PTCL-U, Gisselbrecht et $\mathrm{al}^{8}$ report a 5 -year OS for "peripheral T-cell lymphoma" of $41 \%$, but this value drops to $31 \%$ on withdrawal from the analysis of ALCL.

For these reasons we undertook a large, multicenter, retrospective analysis with the main end point of studying the prognosis of

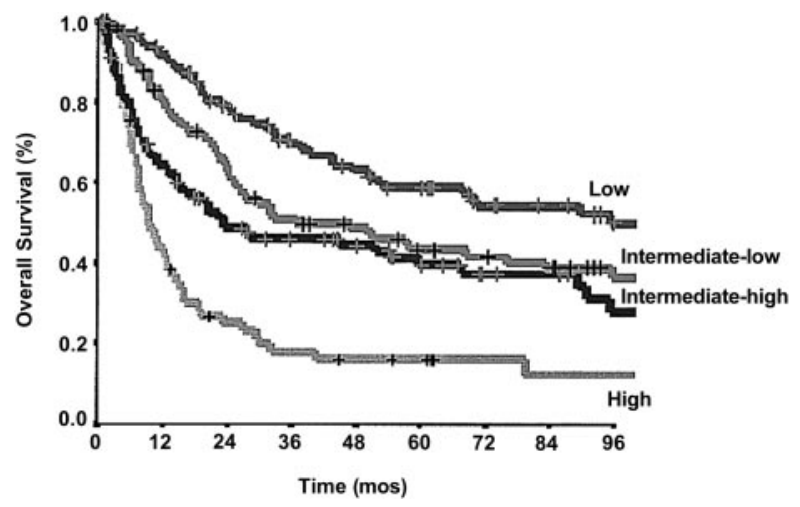

Figure 3. OS according to IPI. Crosses mark censored cases. 


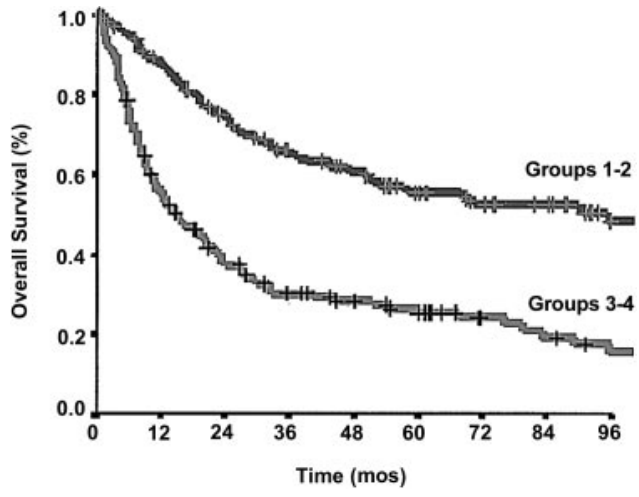

Figure 4. OS according to 2-class, simplified, PIT. Crosses mark censored cases.

PTCL-U patients who were enrolled in the IIL clinical trials during a period of more than a decade. This is, as far as we know, the largest clinical retrospective review on the prognosis of this lymphoma subset. After withdrawal of cases not fulfilling the inclusion criteria, we were able to enroll 385 patients affected by PTCL-U, as defined by the WHO classification. ${ }^{13}$ According to authors, PTCL-U category is an "empty basket" containing several histologic subtypes, characterized by a prevalent nodal presentation and an aggressive but nonspecific clinical behavior. Even if not all cases had a systematic histologic review, we believe that the detailed histopathologic picture, the concurrent immunophenotype, and the exclusion of a number of well-defined clinicopathologic entities, could have further reduced the inclusion of non PTCL-U lymphomas in our series.

The 5-year and the 10-year OS of the patients enrolled in the present study $(43.03 \%$ and $33.50 \%$, respectively) fit in the upper limit of the range reported in the literature. This may be because of the median age, up to 10 years younger than the one reported in other series, ${ }^{8-10,22}$ and the large predominance of patients with ambulatory PS (PS 0-1, 274 of 382, 71.7\%). Both differences could partially reflect a selection of the patients fitting the inclusion criteria for entering into the clinical trials. Finally, unlike other retrospective studies, the present study does not encompass subsets of T-cell lymphomas with a very poor prognosis such as nasal-type T-cell lymphoma and enteropathy-associated T-cell lymphoma.

At this writing, 229 of 385 patients have died, mostly because of disease progression or relapse. The risk of death was higher in the first 2 years since diagnosis and decreased over time; although a true plateau was never reached, $44.1 \%$ and $67.2 \%$ of the deaths were recorded within the first 12 and 24 months, respectively. This pattern of the survival curve (Figure 1) seems also to demonstrate that the therapy was unable to change the course of the disease whatever the strategy chosen; however, the survival of patients attaining CR was significantly longer. High-dose chemotherapy followed by autologous BM transplantation was performed in 44 $(11.8 \%)$ of 372 patients and failed to show any advantage over standard therapy in prolonging survival $(P=.2$; data not shown) This result, in keeping with Rodriguez data, ${ }^{17}$ is not surprising, if one considers the low overall response rate to therapy (53.2\%) that we observed in our study, without statistical differences among the 3 therapeutic strategies $(P=.6)$, and the very aggressive behavior of these neoplasms. However, we are fully aware that no definite conclusions regarding the role of the therapy can be drawn from a retrospective clinical trial with an accrual time spanning more than a decade.

Several studies have been done to assess the contributions of a number of clinical factors to the prognosis. IPI seems to work as well in peripheral T-cell lymphomas as in diffuse large-cell lymphomas ${ }^{8-10,14}$; however, besides IPI, systemic symptoms and $\mathrm{BM}$ infiltration have been found to correlate with prognosis in a single study. ${ }^{9}$

The cytology of the neoplastic cell has long been debated as a prognostic factor. In the REAL classification 3 morphologic variants have been proposed: medium-sized cells, mixed medium and large cells, and large cells, ${ }^{12}$ but because of lack of reproducibility these provisional entities were no longer recognized in the WHO classification. Applying the updated Kiel classification, ${ }^{23}$ Ascani et al, ${ }^{2}$ Noorduyn et al, ${ }^{24}$ and Richards and Stansfield ${ }^{25}$ were unable to find any survival difference between low- and high-grade histologic forms, whereas Rudiger et $\mathrm{al}^{22}$ found that the number of transformed blasts in 10 random high-power fields was prognostically relevant.

Another aim of this study was to check the value of the preexisting prognostic models and to eventually propose a new system to evaluate the outcome of PTCL-U. As in other aggressive lymphomas IPI was able to identify subsets of patients with different prognoses, but in multivariate analysis only 3 of 5 parameters retained their prognostic significance in our study. The extension of the disease (staging) and the presence of ENSs were no longer significant, probably because the disease per se is characterized, in more than two thirds of the patients, by a presentation in advanced stage and in 2 or more ENSs. BM involvement has been associated with a poor response to therapy and a shorter survival in diffuse large-cell B lymphomas ${ }^{23,26}$; in PTCL-U it occurs in $20 \%$ to $40 \%$ of the cases $^{27}$ and seems to worsen the prognosis. ${ }^{2}$ In the present study we observed a BM involvement in a similar proportion of cases, and we confirmed the resulting negative impact on survival. This effect occurred independently from other IPI prognostic factors, probably because of a more pronounced tendency of the tumor to spread. Of the remaining 3 factors prognostically significant in multivariate analysis, 2 are host-related (age, PS) and the third (elevated LDH levels) has been considered a marker of increased cell turnover. ${ }^{28}$

On the basis of these findings we propose a new prognostic model for PTCL-U, which we have called PIT (Prognostic Index for PTCL-U), based on these 4 simple clinical variables: age, PS, LDH level, and BM involvement. PIT seems to differ from IPI because in the former the 2 IPI factors based on the extension of the disease (stage and ENSs) do not seem to work with same efficacy. Conversely, of the 2 PIT factors related to the biology of the tumor (BM involvement and LDH level), only one (LDH level) has a prognostic role in IPI.

The PIT model was able to identify 4 classes of patients with different outcomes, with an overall superior predictive capacity as compared to IPI (log-rank, 66.79 versus 55.94). The same holds true considering a simplified 2-class model obtained by grouping the 4 prognostic classes of IPI and PIT in 2 risk categories: the first containing class 1 and 2 and the second containing class 3 and 4 . Simplified 2-class PIT fared better than simplified 2-class IPI (log-rank, 49.36 versus 30.23; Figure 4).

In conclusion, in addition to better defining risk classification in respect to IPI, the proposed model has shown that nearly half the patients affected by PTCL-U (classified in groups 3 and 4) had a very dismal prognosis, with a 5-year survival probability of only $26.81 \%$. For these patients a new therapeutic strategy (eg, monoclonal antibodies associated with ASCT or allo-BM transplantation) should be explored. 


\section{Appendix}

Participating institutions and principal investigators of the Intergruppo Italiano Linfomi on peripheral T-cell lymphoma include the following: S.C. Ematologia, Azienda ospedaliera S. Croce e Carle, Cuneo (A. Gallamini, D. Mattei, R. Calvi); S.C. Ematologia, Azienda ospedaliera S. Giovanni Battista, Torino (E. Gallo, U. Vitolo); Cattedra di Ematologia Università degli studi di Torino (M. Boccadoro, C. Tarella, M. Ladetto); Divisione di Onco-Ematologia, IRCS Candiolo, Torino (M. Aglietta, D. Rota Scalabrini); S.C. Medicina, Ospedale di Biella (S. Fontana, A. Tonso); S.C. Medicina, Ospedale di Asti (E. Scassa, A. Ciravegna, R. Frieri); Cattedra di Clinica Medica Università Piemonte Orientale (G. L. Gaidano); Divisione di Oncologia Medica C Istituto Nazionale Tumori (A. M. Gianni, L. Devizzi); Cattedra di Ematologia, Ospedale Maggiore, IRCCS, Milano (A. T. Maiolo, L. Baldini); Divisione di Ematologia, Ospedali Riuniti di Bergamo (T. Barbui, S. Cortellazzo); U.SD Ematologia, Spedali Civili Brescia (G. Rossi, E. Tucci); Divisione di Ematologia IRCCS Policlinico S. Matteo, Pavia (M. Lazzarino, E. Brusamolino); Cattedra di Medicina Interna, Università di Pavia, IRCCS Policlinico S. Matteo, Pavia (P. Gobbi, M. Ghirardelli); Dipartimento di Medicina Clinica e Sperimentale, Sezione di Ematologia, Università di Verona (G. Pizzolo, G. Todeschini, F. Benedetti); Dipartimento di Medicina Clinica e Sperimentale, Università di Padova (G. Semenzato, R. Zambello) Divisione di Ematologia, Ospedale Regionale Bolzano (P. Coser, G. Quaini); Cattedra di Ematologia, Università di Udine (R. Fanin, F. Zaja); Divisione Medica Onco-Ematologica
Ospedale Civile, Piacenza (L. Cavanna, R. Bertè); Servizio di Ematologia Arcispedale S. Maria Nuova Reggio Emilia (L. Gugliotta, F. Merli); Cattedra di Ematologia, Università di Modena (G. Torelli);Cattedra di Oncologia Medica, Università di Modena e Reggio Emilia (M. Federico, M. Bellei); Cattedra di Medicina Interna, Università di Modena e Reggio Emilia (S. Sacchi, G. Longo); Cattedra di Ematologia Istituto Seragnoli Università di Bologna (M. Baccarani, P.L. Zinzani); Divisione di Ematologia $1^{\circ}$ Ospedale S. Martino, Genova (G. Santini, M. Congiu); Divisione di Ematologia Università di Pisa Ospedale S. Chiara, Pisa (M. Petrini, F.Caracciolo); Cattedra di Ematologia, Policlinico Careggi, Università di Firenze (A. Bosi, L. Rigacci); Cattedra di Clinica Medica, Università di Ancona (P. Leoni, A. Olivieri); Cattedra di Clinica Medica, Policlinico Monteluce, Perugia (F. Grignani, M. Liberati); -Dipartimento di Biotecnologie Cellulari ed Ematologia Università la Sapienza, Roma (F. Mandelli, M. Martelli); Dipartimento di Oncologia ed Ematologia Ospedale di Pescara (M. Fioritoni F. Angrilli); U.O. Medicina Istituto Oncologico, Bari (G. Colucci, E. Naglieri); -Divisione di Ematologia, Ospedale A. Perrino, Brindisi (G. Quarta); Divisione di Ematologia IRCCS casa del Sollievo e della Sofferenza, S. Giovanni Rotondo (A. Carella, M. Dell'Olio); Dipartimento di Onco.Ematologia, Az. Ospedaliera Bianchi-Melacrino-Morelli, Reggio Calabria (C. Stelitano, F. Morabito); -Divisione di Ematologia Azienda Ospedaliera Papardo Messina (M. Brugiatelli); -Divisione di Ematologia Ospedale Cervello Palermo (S. Mirto C. Patti); Dipartimento di Ematologia, Oncologia e TMO Cattedra di Ematologia Università di Palermo (G. Mariani, E. Iannitto); Divisione di Ematologia Ospedale Businco Cagliari (E. Angelucci G. Cabras).

\section{References}

1. Coiffier B, Berger F, Byron PA, Magaud JP. T-cell lymphomas: immunological, histological, clinical and therapeutic analysis of 63 cases. J Clin Oncol. 1988; 6:1584-1589.

2. Ascani S, Zinzani PL, Gherlinzoni F, et al. Peripheral T-cell lymphomas. Clinico-pathologic study of 168 cases diagnosed according to the R.E.A.L. classification. Ann Oncol. 1997; 8:583-592.

3. The non-Hodgkin's Lymphoma Classification Project. A clinical evaluation of the International Lymphoma Study Group Classification of nonHodgkin's lymphoma. Blood. 1997;89:3909-3918.

4. Cheng AL, Chen YC, Wang CH, et al. Direct comparison of peripheral T-cell lymphoma with diffuse B-cell lymphoma of comparable histological grades. Should peripheral T-cell lymphoma be considered separately? J Clin Oncol. 1989;7:725731.

5. Kwak LW, Wilson M., Weiss LM, et al. Similar outcome of treatment of B-cell and T-cell diffuse large cell lymphomas: the Stanford experience. J Clin Oncol. 1991;9:1426-1431.

6. Coiffier B, Brousse N, Peuchmaur M, et al. Peripheral T-cell lymphomas have a worse prognosis than B-cell lymphomas: a prospective study of 361 immunophenotyped patients treated with the LNH84 regimen. Ann Oncol. 1990;1:45-50, 1990.

7. Melnyk A, Rodriguz A, Pugh WC, Cabanillas F. Evaluation of the revised European-American lymphoma classification confirms the clinical relevance of immunophenotype in 560 cases of aggressive non-Hodgkin's lymphoma. Blood. 1997; 89:4514- 4520.

8. Gisselbrecht C, Gaulard P, Lepage E, et al. Prog nostic significance of T-cell phenotype in aggressive non-Hodgkin's lymphomas. Blood. 1998;92: 76-82.

9. Lopez-Guillermo A, Cid J, Salar A, et al. Peripheral T-cell lymphomas: initial features, natural history and prognostic factors in a series of $174 \mathrm{pa}-$ tients diagnosed according to the REAL classification. Ann Oncol.1998;9:849-855.

10. Ansell SM, Habermann TM, Kurtin PJ, et al. Predictive capacity of the International Prognostic Factor Index in patients with peripheral T-cell lymphomas. J Clin Oncol. 1997;15:2296-2301.

11. Suchi T, Lennert K, Tu LY, et al. Histopathology and immunohistochemistry of peripheral $\mathrm{T}$ cell lymphomas: a proposal for their classification. J Clin Pathol. 1997;40:995-1015.

12. Harris NL, Jaffe ES, Stein $\mathrm{H}$, et al. A revised European-American classification of lymphoid neoplasms: a proposal from the International Lymphoma Study Group. Blood. 1994;84:1361-1392.

13. Harris NL, Jaffe ES, Diebold J, et al. World Health Organization classification of neoplastic diseases of the Hematopoietic and lymphoid tissues: report of the Clinical Advisory Committee meeting-Arlie House, Virginia, November 1997. J Clin Oncol. 1999;17:3835-3849.

14. Zaja F, Russo D, Silvestri F, et al. Retrospective analysis of 23 cases with peripheral T-cell lymphoma, unspecified: clinical characteristics and outcome. Haematologica. 1997;82:171-77.

15. Haioun C, Lepage E, Gisselbrecht C, et al. Benefit of autologous bone marrow transplantation over sequential chemotherapy in poor-risk aggressive non-Hodgkin's lymphoma: updated results of the prospective study LNH87-2. Groupe d'Etude del Lymphomes de l'Adulte. J Clin Oncol. 1997:15:1131-1137.

16. Tarella C, Caracciolo D, Ladetto M, et al. 11-yr follow-up of 184 non-Hodgkin's lymphoma (NHL) patients treated with high-dose sequential (HDS) chemotherapy and autograft: highest response and best outcome in germinal-center derived subtypes [abstract]. Blood. 2000;96:796a.

17. Rodriguez J, Munsell M, Yazji S, et al. Impact of high-dose chemotherapy on peripheral T-cell lymphomas. J Clin Oncol. 2001;19:3766-3770.
18. Nie $\mathrm{HH}$, Hadlai $\mathrm{H}$, Jenkins JG, Steinbrenner $\mathrm{K}$ Bent DH. SPSS (Statistical Package for the Social Sciences). New York, NY: McGraw-Hill; 1979.

19. Kaplan EL, Meier P. Non parametric estimation from incomplete observation. JAMA. 1958;53: 457-481.

20. Mantel N. Evaluation of survival data and two new rank order statistics arising in its consideration Cancer Chemother Rep.1966;50:163-170.

21. Cox DR. Regression models and life-tables. J Stat Soc. 1982;34:187-220.

22. Rudiger T, Weisemburger DD, Anderson JR, et al. Peripheral T-cell lymphoma (excluding anaplastic large-cell lymphoma): results from the nonHodgkin's lymphoma classification project. Ann Oncol. 2002;13:140-149.

23. Vitolo U, Bertini M, Brusamolino E, et al. MACOP-B treatment in diffuse-large cell lymphoma: identification of prognostic groups in an Italian multicentric study. J Clin Oncol. 1992;10: 219-227.

24. Noorduyn $L A$, van der Valk $P$, van Heerde $P$, et al. Stage is a better prognostic indicator than morphologic subtype in primary non cutaneous T-cell lymphoma. Am J Clin Pathol. 1990;93:49-57.

25. Richards MA, Stansfeld A. Updated Kiel classification for lymphomas [letter]. Lancet. 1988;:937.

26. Robertson LE, Redman JR, Butler JJ, et al. Discordant bone marrow involvement in diffuse large-cell lymphoma: a distinct clinico-pathologic entity associated with a continuous risk of relapse. J Clin Oncol. 1991;9:236-242.

27. Hanson CA, Brunning RD, Gajl-Peczalska KJ, Frizzera G, McKenna RW. Bone marrow manifestation of peripheral T-cell lymphoma: a study of 30 cases. Am J Clin Pathol. 1986;86:449-460.

28. Pan L, Beverley PC, Isaacson PG. Lactate dehydrogenase (LDH) isoenzymes and proliferative activity of lymphoid cells. An immunocytochemical study. Clin Exp Immunol. 1991;86:240-245. 